\title{
Modelling the cement process and cement clinker quality
}

Bodil Hökfors MSc, Tech. lic.

Project Leader, Cementa AB, Stockholm, Sweden; Department of Applied Physics and Electronics, Energy Technology and Thermal Process Chemistry, Umeå University, Umeå, Sweden
Matias Eriksson BEng, Tech. lic

Production Manager, NorFraKalk, Verdal, Norway

Erik Viggh BEnvisci

Project Leader, Cementa AB, Malmö, Sweden; PhD student, Umeå University, Umeå, Sweden

This paper presents a recently developed simulation model that can be used as a tool for evaluating sustainable development measures for cement and lime production processes. Examples of such measures are introducing new combustion technologies such as oxy-fuel combustion, using biomass fuel and using alternative materials in the raw material feed. One major issue when introducing process changes is the need to maintain product quality. In some ways, oxygen-enriched air combustion resembles oxy-fuel combustion. The model results were validated and found to be consistent with full-scale operational data for normal running conditions and for a full-scale test with oxygenenriched air. The model shows, for example, that with an additional $1500 \mathrm{~m}^{3} / \mathrm{h}$ of oxygen, fuel addition at the calciners can increase up to $108 \%$ and the raw material feed rate can increase up to $116 \%$ for a process with a raw meal feed of $335.5 \mathrm{t} / \mathrm{h}$.

\section{Introduction}

It is important to understand how changing the atmosphere in a kiln influences clinker quality. This is especially the case considering that future scenarios for the cement industry include carbon capture and storage and oxy-fuel combustion (Barker et al., 2009; WBCSD and IEA, 2009; Zeman, 2008). This paper describes the influence of oxygen-enriched air combustion on the clinker production process and clinker quality. Increased oxygen addition locally increases the concentration of oxygen in the process. The introduction of oxy-fuel combustion techniques will change the composition of the process gases more significantly due to a drastic increase in carbon dioxide $\left(\mathrm{CO}_{2}\right)$ concentration.

Simulation models are tools that will aid the cement industry of today and help continue its development towards sustainability in the future. Models for simulating carbon dioxide emissions and conserving material and fuel resources, as well as implementing energy efficiency measures, have been described by Schneider et al. (2011) and Sorrentino (2011).

\section{Carbon dioxide emissions in cement production}

Owing to the environmental impact of carbon dioxide emissions, carbon-dioxide-intensive industries must strive to decrease emissions. The cement industry emitted a total of $1514 \mathrm{Mt}$ of carbon dioxide in 2009 , which corresponds to $4.7 \%$ of the total global carbon dioxide emissions from fossil fuel burning (Boden and Andres, 2012). Cement is used nearly without exception in concrete. Concrete is the world's most used construction material and its use has increased threefold since 1970, and production of both cement and concrete is expected to increase even further in the future (WBCSD and IEA, 2009). Manufacturers of clinker and cement must enact environmental measures but at the same time maintain the production of good-quality cement while preserving stable running conditions in the manufacturing process.

\section{Oxygen enrichment and oxy-fuel combustion}

A simplified illustration of oxygen-enriched air combustion is shown in Figure 1. The idea is to add highly concentrated oxygen to the process, with the aim of increasing the production of cement clinker for sustainability purposes such as enhancing the combustion of low-grade fuels or improving energy efficiency (Damtoft et al., 2008). Higher raw meal feed is possible when more oxygen is available for the combustion of fuels; fuel feeding can thus increase along with clinker production. Air consists of approximately $79 \mathrm{vol} \%$ nitrogen and $21 \mathrm{vol} \%$ oxygen. The nitrogen only serves as bulk in the system because the whole volume of air needs to be heated in order to reach the desired process temperatures. Thus, the nitrogen content in the air increases energy consumption. The next step is to replace all air with pure oxygen. This technology is called oxy-fuel combustion and is illustrated in Figure 2. An air separation unit (ASU) is used to produce the highly concentrated oxygen. If only oxygen

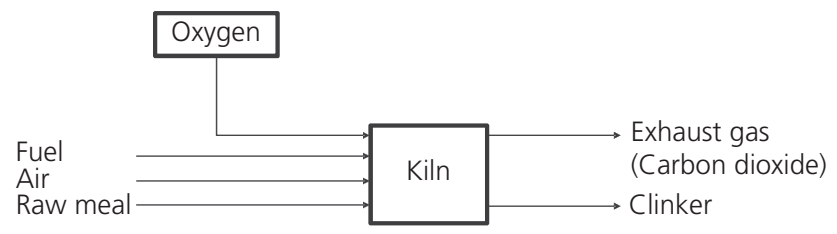

Figure 1. Schematic illustration of oxygen-enriched combustion 


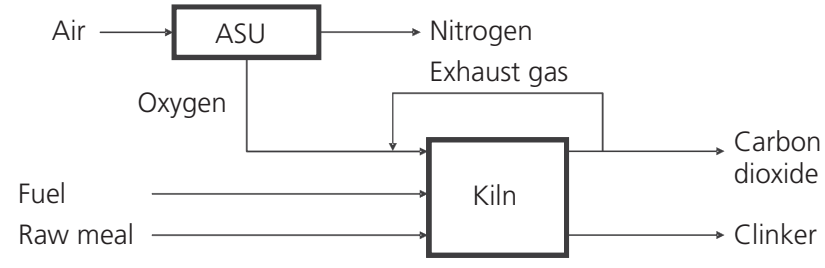

Figure 2. Schematic illustration of oxy-fuel combustion

gas was added to the burning zone, the temperature would be very high. Balancing the temperature is necessary and is achieved by recirculating the exhaust gas back to the burning zone.

\section{Simulation tools}

When introducing new raw materials, new fuels or new combustion technologies, much can be gained if there are simulation tools for predicting the outcomes of the changes. Full-scale industrial tests are very costly. Simulations will not replace fullscale tests, but the required number of tests might be reduced. The development of a simulation tool applicable to the cement kiln process is thus important.

Models for the simulation of cement clinker manufacturing have been developed. Many of the works in the literature describe physical models that focus on flame characteristics, bed motion and heat transfer mechanisms. Some have used computational fluid dynamics (CFD) as the modelling tool (Mastorakos et al., 1999; Yuan et al., 2007) while mathematical equations of energy and mass conservation have been described and applied by others (Locher, 2002; Mujumdar et al., 2006). A chemical model has also been developed that focuses on the intrusion of alkali compounds in the ceramics in the kiln lining using non-equilibrium calculations (Emler, 2008). A steady-state chemical simulation model describing the thermodynamics and high-temperature chemistry of the cement process was presented by Kääntee et al. (2004), the focus of the work being the possibility of using alternative fuels in the cement process. An interesting model was developed by adding additional software and a more complete thermodynamic database to an Aspen Plus model by introducing Fact data (Yokota, 2004). The latter three models use adjustable parameters, which limits applications to specific plants and limited process variations in terms of process parameters. A process model that included plant-specific parameters of a cement plant using thermochemical data from Fact, where no mixed solution phases were included, was developed by Modigell et al. (2002). The linking of coupled chemical equilibrium reactors for modelling the alkali and sulfur chemistry in the cement kiln due to the utilisation of used tyres was explored. The model does not include the complete condensed-phase chemistry, but is a complete counter-current gas and material flow model (Enestam, 1998). A chemical model with a thermodynamic database and the possibility of including reaction kinetics and mass transfer between the bed and the gas phase was described by Pajarre and Penttilä (2004). Benefits of using phase equilibrium calculations in cement clinkering reactions were also presented by Barry and Glasser (2000).

Two groups of researchers have described the simulation of oxygen enrichment in cement rotary kilns. Both works focused on the flame and combustion characteristics, and both used CFD technology as a tool for showing the effects on flame temperature and shape and on combustion speed when using coal as fuel under increased oxygen concentrations (Manickam et al., 2009; Marin et al., 2001).

\section{The cement process and the developed thermodynamic process model}

The main characteristics of the cement manufacturing process are now described, along with the structure and details of the simulation model. The developed model is fully predictable with no adjustable parameters, which means that it is suitable for general use.

\section{Cement manufacturing process}

The thermodynamic process model developed describes a modern dry-feed cement plant process with a double preheater system with calciners. The primary fuels are coal and petroleum coke. Used car tyres are used as an alternative fuel in the calciners along with coal and petroleum coke. The manufacture of cement involves several physical operations and chemical reactions. Figure 3 illustrates the whole chain, from the quarrying of raw material to the end product cement ready for delivery to the customer. After the raw meal has been quarried, it is crushed, ground and fed into the process at the top of the cyclone tower. The process continues with the material being preheated in the cyclones and calciners, entering the riser duct and flowing into the rotary kiln. After reaching the maximum temperature at the lower end of the rotary kiln, the clinker is cooled in a clinker cooler.

One of the main chemical reactions taking place is calcination by removing carbon dioxide from the carbonaceous material. This endothermic reaction consumes energy. In a system with preheating, the calcination is, to a large extent, completed before the material enters the rotary kiln.

The air feed into the process moves in the opposite direction to the material. Air is either added as primary air with the fuel to the main burner at the lower end of the rotary kiln or as secondary air for cooling the clinker. The gas leaves the process as exhaust gas at the top of the cyclones, cools in the cooling tower and is de-dusted in bag filters.

\section{Simulation model}

The simulation model simulates the part of the process where chemical reactions take place. In Figure 4, the model shows the cyclone, preheater, rotary kiln and clinker cooler. The process model comprises two commercial software programs, Aspen Plus and Chemapp. The process scheme is drawn in Aspen Plus and the 


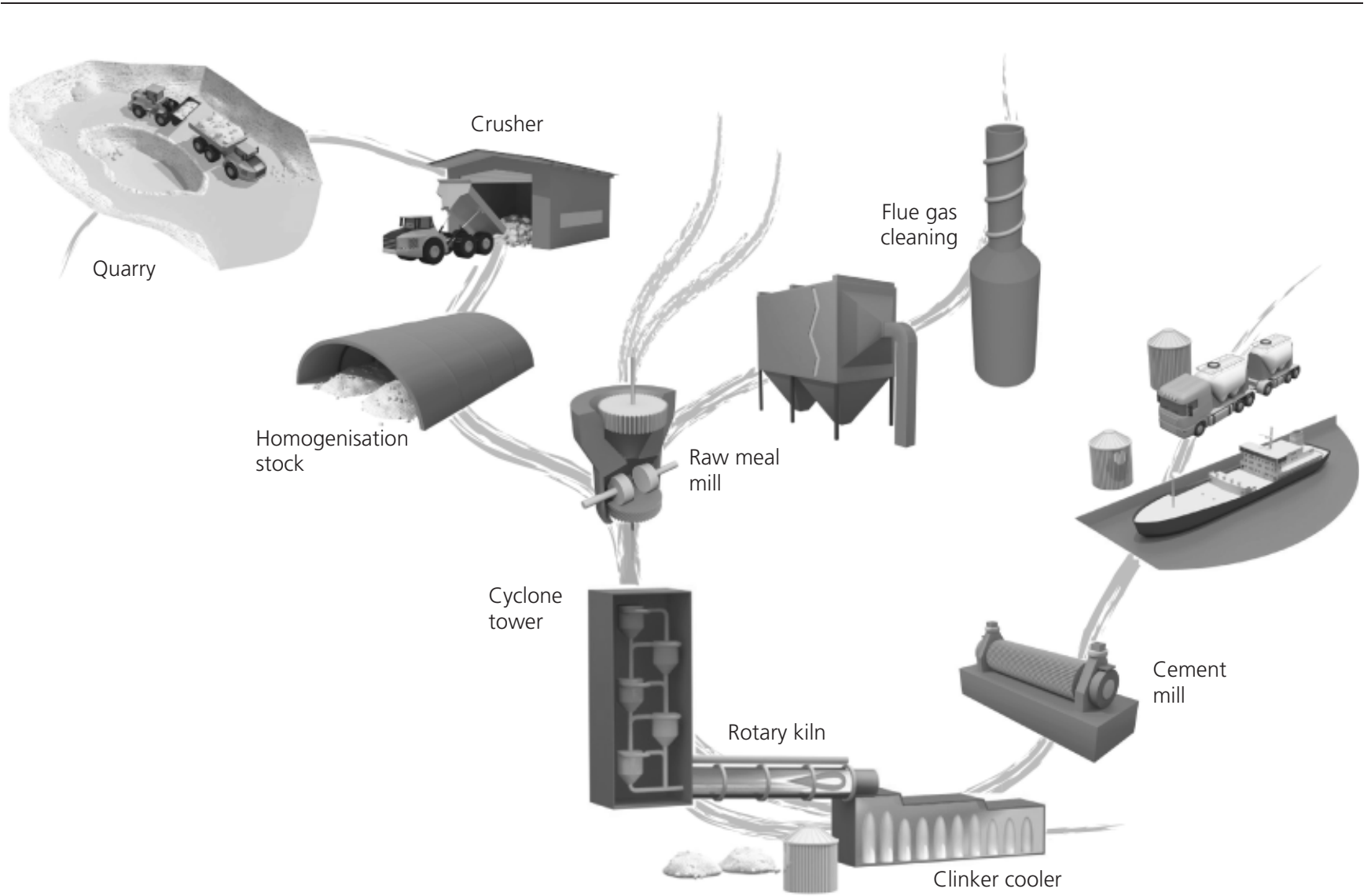

Figure 3. Illustration of a typical cement manufacturing process

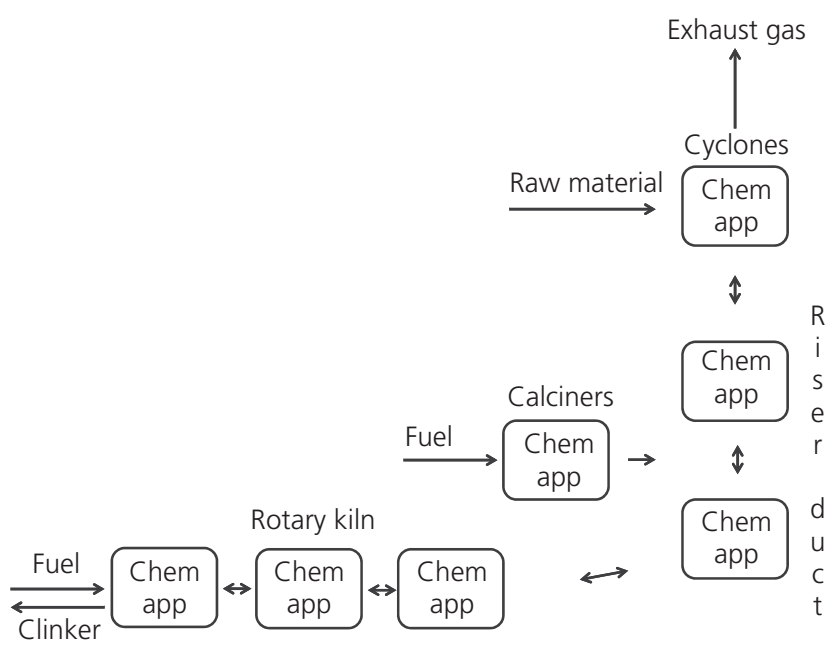

Figure 4. Process layout of the simulation model

iteration procedure continues until it reaches a mass and energy balance. The calculation blocks are placed in the process scheme with Chemapp algorithms wherever chemical equilibrium calculations are necessary. In the model, these are selected to calculate the chemistry in the cyclones, calciners, upper and lower riser ducts, rotary kiln inlet, middle of the kiln and the burning zone.
The model described in this paper is a continuation of one previously developed by Kääntee et al. (2004). The model was further developed with a unique fuel definition and use of Chemapp software. It was verified for a cement plant (Wilhelmsson-Hökfors et al., 2008). Further developments were then made, as described by Hökfors et al. (2012). This time, the model was applied to and verified for a lime rotary kiln. The database was extended to include the solution phases and a non-equilibrium cooling method for the product. The simulation results were compared and verified with full-scale data for the lime manufacturing plant. The model is an idealised model in the sense that it functions in a completely counter-current flow mode with gas moving in one direction and condensed material travelling in the opposite direction. No kinetic factors are considered and chemical equilibrium is reached in every Chemapp block. Calculation of chemical equilibrium for an ideal system involves minimising the Gibbs free energy by optimisation. This implies, for example, that the heat transfer between all involved phases is complete and their temperatures are identical.

The thermodynamic database contains 16 system components (Ca, Si, Al, Fe, Mg, C, H, O, N, K, Na, S, Cl, P, Ti and Zn), one gas phase, two pure liquids (water and calcium sulfate), 173 pure solid phases and nine solution phases. There are two liquid solution phases - an oxide melt with $\mathrm{CaO}, \mathrm{SiO}_{2}, \mathrm{Al}_{2} \mathrm{O}_{3}, \mathrm{Fe}_{2} \mathrm{O}_{3}$, $\mathrm{MgO}, \mathrm{FeO}, \mathrm{TiO}_{2}, \mathrm{Ti}_{2} \mathrm{O}_{3}, \mathrm{ZnO}, \mathrm{K}_{2} \mathrm{O}, \mathrm{Na}_{2} \mathrm{O}, \mathrm{CaSO}_{4}$ and $\mathrm{Ca}_{3}\left(\mathrm{PO}_{4}\right)_{2}$ 
and a salt melt with $\mathrm{KCl}, \mathrm{NaCl}, \mathrm{Na}_{2} \mathrm{SO}_{4}, \mathrm{~K}_{2} \mathrm{SO}_{4}, \mathrm{Na}_{2} \mathrm{CO}_{3}$, $\mathrm{K}_{2} \mathrm{CO}_{3}$ and $\mathrm{CaSO}_{4}$. The other solution phases are solid solutions, such as calcium aluminate ferrites, alkali salts and calcium titanium oxides. The thermodynamic data are from Fact.

The fuels are defined uniquely by their chemical compositions and calorimetric heating values, as described by Wilhelmsson-Hökfors et al. (2008). The properties of the fuels used in the model are shown in Table 1. Coal and petroleum coke are used in the burn zone and in the calciners. Used car tyres are added in the calciners. Table 2 lists the compositions of the raw materials fed into the process.

Temperatures in the model are enthalpy controlled. It is also possible to specify the temperature in each Chemapp block, but it is necessary to use enthalpy-steered calculations to predict how the process changes influence the temperature.

\section{Results}

The results described are from the simulation model. Because the model has been subjected to improvement, it is first compared and

\begin{tabular}{lccc}
\hline & Coal & $\begin{array}{c}\text { Petroleum } \\
\text { coke }\end{array}$ & $\begin{array}{c}\text { Used car } \\
\text { tyres }\end{array}$ \\
\hline Carbon: wt\% & 67.8 & 86.2 & 67.6 \\
Hydrogen: wt\% & 4.3 & 3.1 & 7.0 \\
Oxygen: wt\% & 11.4 & 0.9 & 1.3 \\
Nitrogen: wt\% & 1.2 & 1.7 & 0.4 \\
Sulfur: wt\% & 0.33 & 7.5 & 1.6 \\
Chlorine: wt\% & 0.001 & 0.004 & 0.1 \\
Ash: wt\% dry matter & 14.95 & 0.60 & 21.90 \\
Maximum heating value: & 31.72 & 35.05 & 33.20 \\
MJ/kg dry matter & \multicolumn{3}{c}{6.8} \\
Total moisture: wt\% & 9.7 & 1.6 \\
Table 1. Selected properties of fuels used in the model \\
\hline
\end{tabular}

\begin{tabular}{lc}
\hline & Content \\
\hline Calcium carbonate: wt\% & 77.97 \\
Silica: wt\% & 13.76 \\
Aluminium oxide: wt\% & 2.61 \\
Iron (III) oxide: $w t \%$ & 1.67 \\
Magnesium oxide: $w t \%$ & 1.74 \\
Titanium dioxide: $w t \%$ & 0.15 \\
Phosphorus pentoxide: wt\% & 0.02 \\
Potassium oxide: $w t \%$ & 0.77 \\
Sodium oxide: $w t \%$ & 0.2 \\
Sulfur trioxide: $w t \%$ & 1.04 \\
Calcium chloride: $w t \%$ & 0.06 \\
Zinc oxide: $w t \%$ & 0.01 \\
Table 2. Chemical composition of raw meal & \\
\hline
\end{tabular}

validated with reference operational data. It is further compared with a short full-scale operational oxygen-enriched air combustion test. The results describe how the process reacts to changes in combustion air, fuel input and raw meal addition because the model is able to provide detailed process data. The energy demand for oxygen production is not included in the calculations.

\section{Validation of process model}

The process model was validated with operational data from an industrial full-scale process during stable running conditions. Some operational results from normal running conditions are compared with the simulation results in Table 3.

The amount of product is approximately $2 \%$ higher in the simulation model than in the operational data. This is because no particles are entrained in the gas phase in the simulation model. In the operational process, a non-negligible amount of dust is captured in the gas cleaning equipment. Furthermore, there is a small discrepancy in the burning zone temperature between the operational and simulated data. The temperature in the simulation model is an equilibrium temperature, meaning that the temperature is equal across all chemical phases. The operational data show the measured temperature of the solid material including solutions. The temperature of the gas phase is most likely higher in all parts of the system. Because the temperature of the solid phase in the process is of the utmost importance for the quality of the product, it is meaningful to use this as a basis for comparison. The higher oxygen concentration at the cyclones in the process compared with the model is due to less air leakage in the latter.

According to Table 3, the different results between the opera-

\begin{tabular}{|c|c|c|}
\hline & $\begin{array}{c}\text { Operational } \\
\text { data }\end{array}$ & $\begin{array}{c}\text { Simulation } \\
\text { data }\end{array}$ \\
\hline Clinker: t/h & 223 & 227 \\
\hline $\begin{array}{l}\text { Amount of fuel in burning zone: } \\
\% \text { of total energy }\end{array}$ & 54 & 54 \\
\hline Temperature in burning zone: ${ }^{\circ} \mathrm{C}$ & 1370 & 1399 \\
\hline \multicolumn{3}{|l|}{ Concentration of oxygen: vol. \% } \\
\hline Top cyclones & $6 \cdot 0$ & $5 \cdot 0$ \\
\hline Kiln inlet & $2 \cdot 4$ & $2 \cdot 3$ \\
\hline \multicolumn{3}{|l|}{ Chemical composition of clinker: wt\% } \\
\hline Tricalcium silicate (alite) & $69 \cdot 7$ & $65 \cdot 2$ \\
\hline Dicalcium silicate (belite) & $10 \cdot 7$ & $11 \cdot 7$ \\
\hline $\begin{array}{l}\text { Tetracalcium alumino ferrite } \\
\text { (ferrite) }\left((\mathrm{CaO})_{4} \cdot \mathrm{Al}_{2} \mathrm{O}_{3} \mathrm{Fe}_{2} \mathrm{O}_{3}\right)+ \\
\text { tricalcium aluminate })(\text { celite }) \\
\left(\mathrm{CaO}_{3} \cdot \mathrm{Al}_{2} \mathrm{O}_{3}\right)\end{array}$ & $13 \cdot 3$ & $14 \cdot 6$ \\
\hline Free lime & 0.8 & 0.6 \\
\hline Miscellaneous & $5 \cdot 5$ & 7.9 \\
\hline
\end{tabular}

Table 3. Comparison of operational data and simulated data for a reference case 
tional and simulated clinker compositions are partly due to the different methods used to determine the clinker minerals. The operational data are from the evaluation of etched clinker minerals using microscopy, whereas the simulated clinker quality is determined by calculating the equilibrium condensed product at the maximum temperature using a Scheil-Gulliver cooling procedure (Bale et al., 2009).

\section{Operational and simulation results from oxygen- \\ enriched air combustion}

Full-scale tests with oxygen-enriched air were performed with $1500 \mathrm{~m}^{3} / \mathrm{h}$ oxygen (95 vol.\% oxygen, $160 \mathrm{kPa}$ ) added to the primary air. The test aimed to increase clinker production by introducing oxygen, which would improve fuel combustion and, at the same time, allow possibilities for increasing the fuel feed rate. Extra fuel was added in the calciners. The full-scale test was of short duration and therefore simulations were performed to locate the operational steady state not achieved during the full-scale test. The simulated oxygen enrichment test was performed by adding the same amount of oxygen to the primary air as in the test. The extra oxygen in the process was utilised to combust additional fuel. The amount of fuel added to reach the reference-level oxygen concentration was simulated iteratively. The increased temperature resulting from the extra added fuel was then utilised to add more raw meal. Compared with the reference case, the simulations considered $106 \%, 108 \%$ and $110 \%$ of fuel in the calciners.

The oxygen concentrations resulting from the simulations are shown in Figure 5. Approximately 108\% fuel addition to the calciners (compared with the reference case) yielded similar levels of oxygen in the riser and top cyclones. In all simulations, compared with the reference case, the oxygen concentrations

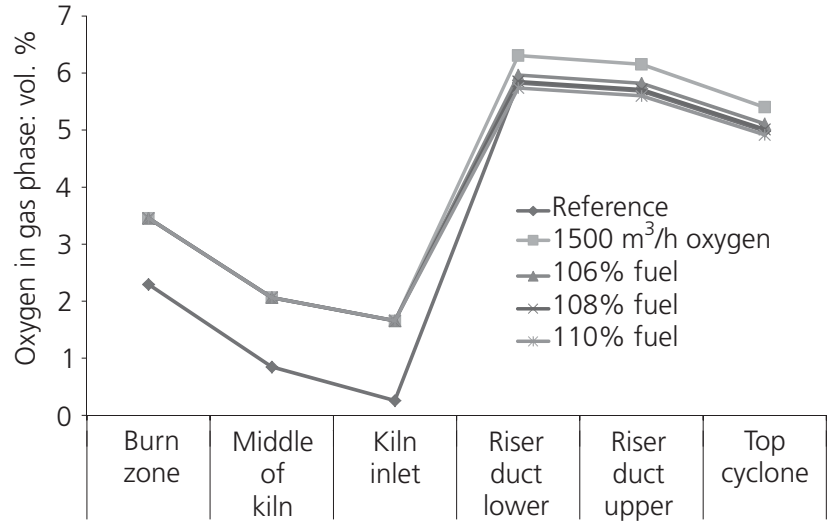

Figure 5. Oxygen concentration in various parts of the process at the reference level, with oxygen addition and with additional fuel feed in calciners of 6,8 and $10 \mathrm{wt} \%$

were higher in the burn zone and the middle and inlet of the rotary kiln. This is because no additional combustion occurs in the burn zone because the fuel rate in this part is kept constant. The gas from the calciners will not reach the rotary kiln because that is in the opposite direction to the gas path. The outcome of this iteration is that it is possible to add $108 \%$ fuel in the calciners at this oxygen level.

Increasing the amount of fuel yields higher temperatures in the process. The increased temperature is utilised to add more raw meal, which enables more endothermic reactions to take place. Simulations were performed with up to $120 \%$ of the raw meal feed rate compared with the reference case; the results are shown in Figure 6. When increasing the raw meal feed rate, more energy is

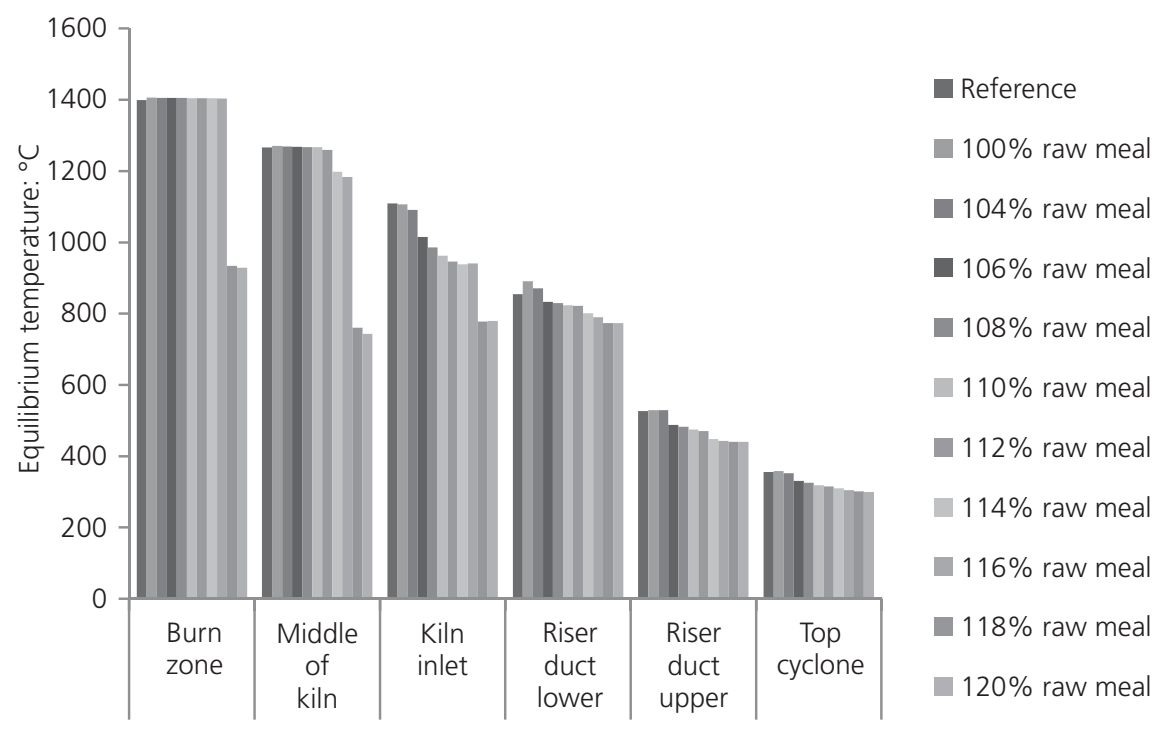

Figure 6. Equilibrium temperatures in different parts of the process at the reference level and with oxygen addition, 108\% fuel feed in the calciners and raw meal feed rates of $100-120 \%$ 
needed to produce clinker, which lowers the temperature. From $104 \%$ to $116 \%$ raw meal addition, decreases in temperature occur in all parts of the process except in the burn zone and in the middle of the kiln. Calcination is the chemical reaction that consumes the most energy in clinker manufacturing and this reaction takes place at approximately $900^{\circ} \mathrm{C}$. In the reference case, this corresponds to the lower part of the riser duct and the kiln inlet. Thus, it is logical that this is where the temperature decrease is most pronounced when increasing the raw meal feed rate.

For a good-quality product, the most important factor is to achieve the projected temperature in the burn zone, which enables the formation of the most important clinker minerals. The required temperature was reached in the burn zone for up to $116 \%$ addition of raw meal. At $118 \%$ and $120 \%$ raw meal addition, there were drastic reductions in temperature in both the burn zone and the middle part of the kiln. The energy input in the calciners is not sufficient to completely calcine the material in the riser or at the kiln inlet. The conclusion is that, for a cement plant with a raw meal feed of $335.5 \mathrm{t} / \mathrm{h}$ and the addition of $1500 \mathrm{~m}^{3} / \mathrm{h}$ of oxygen, $8 \%$ more fuel can be added in the calciners. This allows for a $116 \%$ addition of raw meal while maintaining product quality. Another consequence is that the temperature profile of the process changes. The temperature is lowered at the kiln inlet, in the riser duct and in the cyclones, which leads to decreased energy losses with the exhaust gases.

The main findings are presented in Table 4 together with the simulation results for similar process changes. The results from the full-scale operational test showed an increase of $20 \%$ more clinker production when oxygen-enriched air combustion was tested compared with normal running conditions. The specific energy consumption increased by $2 \%$, but the expected result for energy efficiency would be a decrease. The reasons for the slight increase are the process not being optimised, uncertainty in the measuring device and too short a testing period, which does not reflect a stable process. Owing to lack of experience of using oxygen in combustion at full scale, the fuel feed was needlessly high. The increased gas volume caused by adding extra oxygen could also be the reason for the decreased energy efficiency.

The simulated production increase when using oxygen was calculated to be close to the operational value. The calculated specific energy change for the simulation showed a decrease of

\begin{tabular}{lcc}
\hline & $\begin{array}{c}\text { Operational data } \\
\text { change: } \%\end{array}$ & $\begin{array}{c}\text { Model data } \\
\text { change: \% }\end{array}$ \\
\hline Clinker: $\mathrm{t} / \mathrm{h}$ & +20 & $+17 \cdot 5$ \\
Energy: $\mathrm{kJ} / \mathrm{kg}$ clinker & +2 & -11.8 \\
Table 4. Operational data and simulated data from oxygen \\
enrichment test
\end{tabular}

$11.8 \%$ per kilogramme of clinker produced. One reason for the decreased specific energy consumption is that the process becomes more energy efficient because the temperature of the gas leaving the process is lower in the oxygen enrichment test than in the reference case: $305^{\circ} \mathrm{C}$ compared with $356^{\circ} \mathrm{C}$.

The quality of the clinker produced from the full-scale oxygen enrichment test was evaluated using microscopy. Compared with the reference clinker, the quality was unaffected. The simulated clinker quality from the reference case and the clinker produced with oxygen-enriched air optimised with fuel and raw meal addition are compared in Table 5. There are changes in the amounts of $\mathrm{C}_{3} \mathrm{~S}\left((\mathrm{CaO})_{3} \cdot \mathrm{SiO}_{2}\right.$ (alite)) and $\mathrm{C}_{2} \mathrm{~S}\left((\mathrm{CaO})_{2} \cdot \mathrm{SiO}_{2}\right.$ (belite) - alite increases by $1 \cdot 3 \%$ and belite decreases by $1 \cdot 0 \%$. In total, the change of alite and belite is only $0 \cdot 3 \%$. Sodium oxide, together with potassium oxide and calcium sulfate decreases by $0 \cdot 1 \%$. The changes are due to the smaller amount of fuel and, consequently, less fuel ash is produced per tonne of clinker produced.

The chemical composition of clinker is predicted with a high level of detail by the simulation model. Simulations were performed to determine how increased oxygen enrichment influences clinker quality. The addition of oxygen was tripled compared with the full-scale oxygen enrichment test; all other parameters were kept constant to exclusively evaluate the oxygen addition. The addition of oxygen gas changed the temperature in the process only slightly. The quality of clinker was unaffected by the addition of oxygen up to $4500 \mathrm{~m}^{3} / \mathrm{h}$ without changing the fuel and raw meal feed rates.

\section{Conclusions}

The process model developed for application to cement manufacturing processes adequately predicted a full-scale reference case,

\begin{tabular}{|c|c|c|}
\hline & Reference & $\begin{array}{l}\text { Oxygen- } \\
\text { enriched } \\
\text { air } \\
\text { conditions }\end{array}$ \\
\hline Tricalcium silicate (alite): wt\% & $65 \cdot 2$ & $66 \cdot 5$ \\
\hline Dicalcium silicate (belite): wt\% & $11 \cdot 7$ & $10 \cdot 7$ \\
\hline $\begin{array}{l}\text { Tetracalcium alumino ferrite (ferrite }+ \\
\text { tricalcium aluminate) (celite) }+C_{3} A: \text { wt } \%\end{array}$ & $14 \cdot 6$ & $14 \cdot 5$ \\
\hline Free lime: wt\% & 0.6 & 0.6 \\
\hline Magnesium oxide: wt\% & $2 \cdot 5$ & $2 \cdot 5$ \\
\hline Potassium sulfate + sodium sulfate: wt\% & $2 \cdot 3$ & $2 \cdot 3$ \\
\hline Potassium oxide + sodium oxide: wt\% & 0.6 & 0.5 \\
\hline Calcium sulfate: wt\% & $1 \cdot 7$ & 1.6 \\
\hline Calcium titanate (perovskite): wt\% & $0 \cdot 5$ & $0 \cdot 5$ \\
\hline Potassium calcium sulfate: wt\% & $0 \cdot 4$ & $0 \cdot 4$ \\
\hline
\end{tabular}

Table 5. Simulated reference clinker quality and clinker produced under oxygen-enriched air conditions 
including the amount and quality of product, gas composition and temperatures in the process.

The oxygen enrichment case was predicted well in terms of production increase, but there was a discrepancy when simulating the specific energy consumption. This is because the operational process was not optimised, measurement of the process parameters was imprecise and the test was too short. Oxygen enrichment simulations yielded valuable results for process parameters changes such as oxygen concentration and temperature, when optimising fuel and raw meal feed rates. Under the addition of $1500 \mathrm{~m}^{3} / \mathrm{h}$ oxygen $(95 \%$ vol. $\%$ oxygen) to a cement process feed with $335.5 \mathrm{t}$ raw meal per hour, there are possibilities of increasing clinker production by $17 \cdot 5 \%$ while reducing the specific energy consumption by $11 \cdot 8 \%$.

The quality of the clinker was found to be unaffected by the addition of oxygen up to $4500 \mathrm{~m}^{3} / \mathrm{h}$ without changing the fuel and raw meal feed rates.

The simulation model predicts quality and process changes in the cement clinker production process fairly well when introducing oxy-fuel combustion. It is also a useful tool for evaluating other sustainability measures such as the combustion of low-grade fuels and improvements in energy efficiency and product quality.

\section{Acknowledgements}

Thanks are owed to Bo-Erik Eriksson, Thomas Lind, Anders Lyberg and Stefan Sandelin at Cementa AB, Kjell Dahlberg at Nordkalk Oy Abp, Rainer Backman at Umeå University and Jan Bida and Marianne Thomaeus at MinFo-Swedish Mineral Processing Research Association. Financial support from the Swedish Energy Agency (no. 2006-06679, project 30527-1) and from the Swedish National Research Platform Bio4Energy is also acknowledged.

\section{REFERENCES}

Bale CW, Bélisle E, Chartrand P et al. (2009) FactSage thermochemical software and databases - recent developments. Calphad: Computer Coupling of Phase Diagrams and Thermochemistry 33(2): 295-311.

Barker DJ, Turner SA, Napier-Moore PA, Clark M and Davison JE (2009) $\mathrm{CO}_{2}$ capture in the cement industry. Energy Procedia 1(1): 87-94.

Barry TI and Glasser FP (2000) Calculations of Portland cement clinkering reactions. Advances in Cement Research 12(1): 19-28, http://dx.doi.org/10.1680/adcr.2000.12.1.19.

Boden T and Andres B (2012) Global, Regional and National $\mathrm{CO}_{2}$ Emissions. Carbon Dioxide Information Analysis Center, Oak Ridge, TN, USA.

Damtoft J, Lukasik J, Herfort D, Sorrentino D and Gartner E (2008) Sustainable development and climate change initiatives. Cement and Concrete Research 38(2): 115-127.

Emler R (2008) Dynamic programming using the SimuSage component library and its application to the simulation of the cement clinker burning process. GTT Annual Workshop, Aachen, Germany. See http://gtt.mch.rwth-aachen.de/gtt-web/ gtt-annual-workshop-2008 (accessed 25/09/2013).

Enestam S (1998) Modelling the Alkali and Sulphur Chemistry in the Cement Kiln - The Influence of Using Car Tyres as Additional Fuel. Åbo Akademi, Åbo, Finland.

Hökfors B, Eriksson M and Backman R (2012) Improved process modeling for a lime rotary kiln using equilibrium chemistry. Journal of Engineering Technology Spring: 8-18.

Kääntee U, Zevenhoven R, Backman R and Hupa M (2004) Cement manufacturing using alternative fuels and the advantages of process modelling. Fuel Processing Technology 85(4): 293-301.

Locher G (2002) Mathematical models for the cement clinker burning process - part 5: complete plant. ZKG International 55(7): $1-11$.

Manickam B, Dinkelacker T and Lobe M (2009) Enriched oxygen combustion simulation for rotary kiln application.

Proceedings of European Combustion Meeting, Vienna, Austria.

Marin O, Charon O, Dugue J, Dukhan S and Zhou W (2001) Simulating the impact of oxygen enrichment in a cement rotary kiln using advanced computational methods. Combustion Science and Technology 164(1): 193-207.

Mastorakos E, Massias A, Tsakiroglou CD et al. (1999) CFD predictions for cement kilns including flame modelling, heat transfer and clinker chemistry. Applied Mathematical Modelling 23(1): 55-76.

Modigell M, Liebig D, Munstermann S and Witschen A (2002) Calculation of the clinker burning process using thermochemical process simulation. ZKG International 55(7): $8-46$.

Mujumdar SK, Arora A and Ranade V (2006) Modeling of rotary cement kilns: application to reduction in energy consumption. Industrial and Engineering Chemistry Research 45(7): 23152330.

Pajarre R and Penttilä K (2004) KilnSimu - a ChemSheet based simulator for rotary kilns. GTT Annual Workshop, Aachen, Germany. See http:/gtt.mch.rwth-aachen.de/gtt-web/gttannual-workshop-2004 (accessed 25/09/2013).

Schneider M, Romer M, Tschudin H and Bolio H (2011) Sustainable cement production - present and future. Cement and Concrete Research 41(7): 642-650.

Sorrentino F (2011) Chemistry and engineering of the production process: state of the art. Cement and Concrete Research 41(7): 616-623.

WBCSD and IEA (2009) Cement Technology Roadmap: Carbon Emission Reductions up to 2050. See http://www.iea.org/ publications/freepublications/publication/Cement.pdf (accessed 26/09/2013).

Wilhelmsson-Hökfors B, Viggh E and Backman R (2008) A predictive chemistry model for the cement process. $Z K G$ International 61(7): 60-70.

Yokota M (2004) Application of Aspen/Fact/ChemApp interface for clinker I burning process simulation. Proceedings of 
Aspen Simulation World User Group, Orlando, FL, USA. Yuan J, Darabi P and Salcudean M (2007) Modelling of flow, combustion, clinker formation and $\mathrm{NO}_{\mathrm{x}}$ emissions in long rotary cement kilns. ZKG International 60(12): 54-67.

Zeman F (2008) Clinker formation in atmospheres dominated by nitrogen and carbon dioxide. ZKG International 61(5): 58-67.

\section{WHAT DO YOU THINK?}

To discuss this paper, please submit up to 500 words to the editor at journals@ice.org.uk. Your contribution will be forwarded to the author(s) for a reply and, if considered appropriate by the editorial panel, will be published as a discussion in a future issue of the journal. 